\title{
Rossby wave propagation into the tropical stratosphere observed by the High Resolution Doppler Imager
}

\author{
D. A. Ortland \\ Space Physics Research Laboratory, Department of Atmospheric, Oceanic and Space Sciences, \\ University of Michigan, Ann Arbor, Michigan
}

\begin{abstract}
Stratospheric wind observations by the High Resolution Doppler Imager on the Upper Atmosphere Research Satellite show that quasi-stationary Rossby waves propagate into the tropics. Rossby wave breaking and dissipation causes meridional transport and direct deposition of momentum, and has a significant influence on the evolution of the mean tropical winds in the upper stratosphere. Deeper penetration into the tropics occurs when the quasi-biennial oscillation is in its westerly phase above $30 \mathrm{~km}$. During northern winter, subtropical momentum deposition by Rossby waves occurs only in late November through December, while during southern winter this occurs primarily in August and September.
\end{abstract}

\section{Introduction}

Rossby waves propagate equatorward from the winter hemisphere, and provide a link between the midlatitude and the tropical dynamics. There has been some question as to how much of a role Rossby waves play in tropical dynamics. It is uncertain whether dissipation or breaking of Rossby waves supplies a significant amount of easterly forcing for the quasibiennial oscillation (QBO) [Dunkerton, 1983] or the stratopause semiannual oscillation [Delisi and Dunkerton, 1988; Hamilton and Mahlman, 1988]. Global measurements of the stratosphere are required to answer this question. In the past, only global measurements of temperature have been available, but the Rossby wave signal in temperatures is proportional to the Coriolis parameter, and therefore weak in the tropics. Global wind measurements in the stratosphere up to $40 \mathrm{~km}$ are now available from the high resolution Doppler imager (HRDI) on the Upper Atmosphere Research Satellite (UARS), which has been making observations from November 1991 to the present. These measurements show that Rossby wave propagation into the tropics does indeed occur, primarily when the QBO westerly winds reside at $30 \mathrm{~km}$ over the equator. This paper presents a description of one of these events in HRDI data and some discussion of the role Rossby waves play in the tropical momentum budget.

\section{Data Analysis}

A complete description of the HRDI wind measurement technique may be found in Ortland et al. [1996]. HRDI measures wind vectors about every $6^{\circ}$ along a path to one side of the UARS orbit track. Maps of the horizontal wind field measured on each day were made by interpolating to a regular $10^{\circ} \times 5^{\circ}$ longitudelatitude grid. Latitudinal coverage varies from day to day as the orbit precesses and depends on the side of the orbit track that

Copyright 1997 by the American Geophysical Union.

Paper number 97GL02001.

0094-8534/97/97GL-02001\$05.00
HRDI is viewing on a given day. These maps were then averaged over either a two-week or month-long time interval to reduce random measurement errors and to bring out the signal of the quasi-stationary Rossby wave. Such maps can be produced at the HRDI altitude sampling grid from 10 to $40 \mathrm{~km}$ at $2.5-\mathrm{km}$ intervals.

These maps were used to calculate the Eliassen-Palm (EP) Flux vectors $F=\left(F_{\varphi}, F_{z}\right)$, where (see Andrews et al. [1987] for the standard notation):

$$
\begin{gathered}
F_{\varphi}=\rho_{0} a \cos \varphi\left[\bar{u}_{z} \frac{\overline{v^{\prime} \theta^{\prime}}}{\bar{\theta}_{z}}-\overline{v^{\prime} u^{\prime}}\right] \\
F_{z}=\rho_{0} a \cos \varphi\left[\left(f-\frac{(\bar{u} \cos \varphi)_{\varphi}}{a \cos \varphi}\right) \overline{\frac{v^{\prime} \theta^{\prime}}{\bar{\theta}_{z}}}\right] .
\end{gathered}
$$

In Equation (2) it is assumed that the vertical flux of zonal momentum is negligible for Rossby waves. The HRDI wind field maps are used to calculate the meridional flux of zonal momentum in Equation (1). The heat flux terms were calculated as follows. First, the wind maps were used to calculate the vertical component of vorticity and then the Poisson equation was solved for the horizontal perturbation stream function $\psi^{\prime}$. The stream function is related to the perturbation potential temperature by incorporating the geostrophic and hydrostatic approximations:

$$
\theta^{\prime} / \bar{\theta}_{z}=f \psi_{z}^{\prime} / N^{2}
$$

A value of $\mathrm{N}^{2}=5 \times 10^{-4}$ for the buoyancy frequency squared was used.

The EP flux vectors are parallel to the meridional projection of the group velocity vectors for Rossby waves if the WKB approximation is valid [Edmon et al., 1980], and thus are useful for showing how the Rossby waves propagate. The divergence of the EP flux vectors gives the Rossby wave contribution to forcing of the zonal mean zonal momentum (referred to here as the body force):

$$
D_{F}=\frac{1}{\rho_{0} a \cos \varphi} \nabla \cdot F .
$$

It should be noted that the time averaging performed on the data filters out the traveling waves and may resuilt in an underestimation of the total planetary wave body force in the tropics.

\section{Results}

Quasi-stationary Rossby waves propagate upward from their source region in the troposphere and equatorward through the westerlies of the winter hemisphere. Penetration into the tropics and into the summer hemisphere is observed to occur in November and December of 1992 and 1994. It was during these 

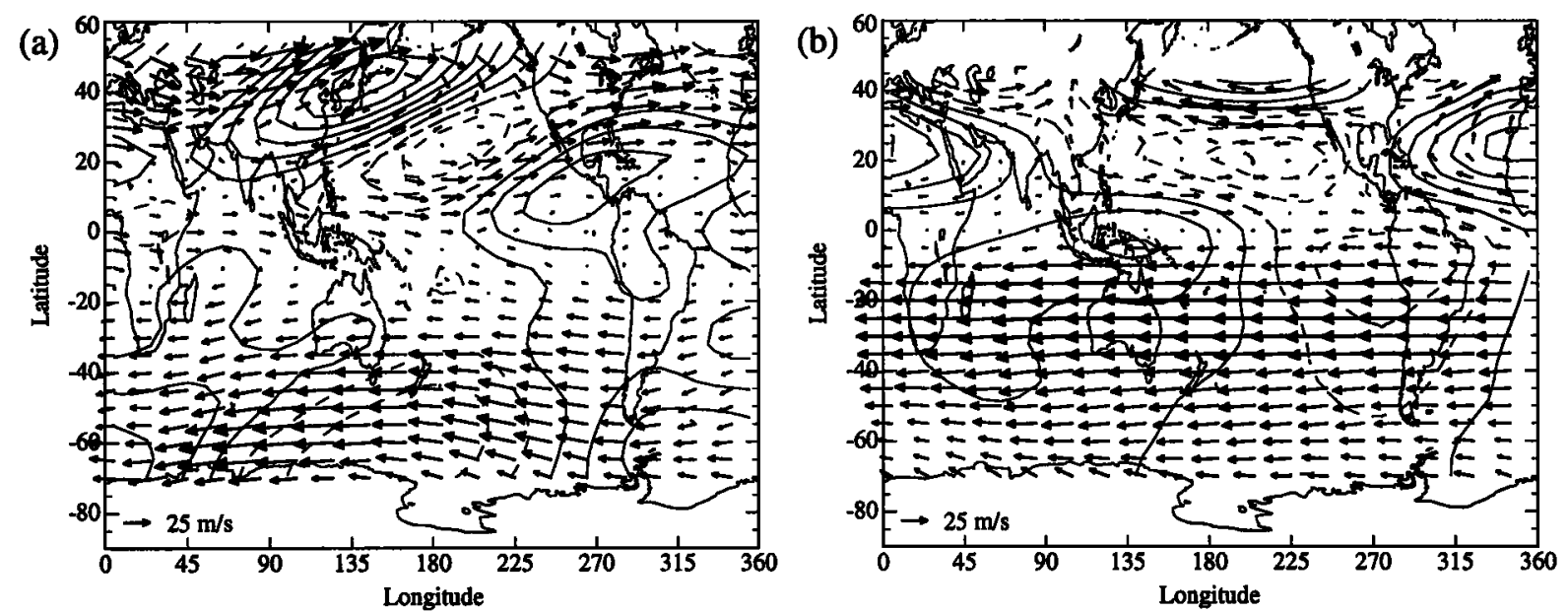

Figure 1. Wind field at $35 \mathrm{~km}$ and contours of the perturbation stream function from (a) November 16-30, 1994, and (b) January 1-15, 1995.

years that QBO westerlies were centered above $25 \mathrm{~km}$ over the equator. Beginning in November, seasonal westerlies form in the northern winter subtropics and provide a means for stationary waves to propagate from the midlatitudes into the tropics. A particularly striking example, shown in Fig. 1, occurred late in November 1994. Figure la shows the wind field in late November 1994 at $35 \mathrm{~km}$, with contours of the perturbation stream function overlaid. A strong anticyclone over the northwestern Pacific is embedded in the northern hemisphere westerlies, and may be viewed as a predominantly wave number 1 disturbance to zonal mean flow. Note that the zonal mean winds at the equator are westerly, but a region of easterlies occurs to the west of South America. The zero wind line, or critical latitude for stationary Rossby waves, is about $15^{\circ}$ south of the equator (see also Fig. 2). The perturbation stream function contours show the characteristic pattern of equatorward propagation, with phase lines tilting from southwest to northeast.

Figure $1 \mathrm{~b}$ shows how the wind field has evolved in early January 1995 at $35 \mathrm{~km}$. The anticyclone has grown in strength and moved eastward and poleward from its position in November, knocking the center of the polar vortex considerably off of the pole. The zonal mean winds have evolved so that the critical latitude lies just north of the equator, confining the wave activity to the northern hemisphere. The perturbation stream function contours no longer show a pattern of equatorward propagation. Since the perturbation amplitude is so large, the dynamics may no longer be conveniently describable in terms of wave propagation on a zonal mean basic state.

The mean winds evolve rapidly throughout November and December of 1994. In early November (not shown), westerly winds in the tropics extend from 22.5 to $40 \mathrm{~km}$ and are surrounded by easterlies in the subtropics. From mid-November (Fig. 2a) to mid-December westerlies form in the northern subtropics, which allows Rossby waves to penetrate to the equator. Strong easterlies begin to extend from the southern hemisphere into the tropics above $35 \mathrm{~km}$, forming an easterly shear zone that causes the upper boundary of the QBO westerlies to descend. In late December (Fig. 2b) the easterlies in the upper stratosphere extend well into the northern subtropics, marking the easterly phase of the stratopause SAO, and the onset of the next easterly phase of the QBO. Note also that the QBO westerlies have been slightly advected into the northern hemisphere. The same sequence of events was played out in 1992 as well (not shown), indicating that there may be some synchronization of the start of the next easterly phase of the QBO with the annual cycle [Dunkerton and Delisi, 1997].

A time latitude section of the daily mean zonal wind at $35 \mathrm{~km}$ (Fig. 3) shows the evolution of the winds in a little more detail. Westerlies are strongly advected northward at $35 \mathrm{~km}$ and disappear rapidly in early winter. The subtropical winds undergo
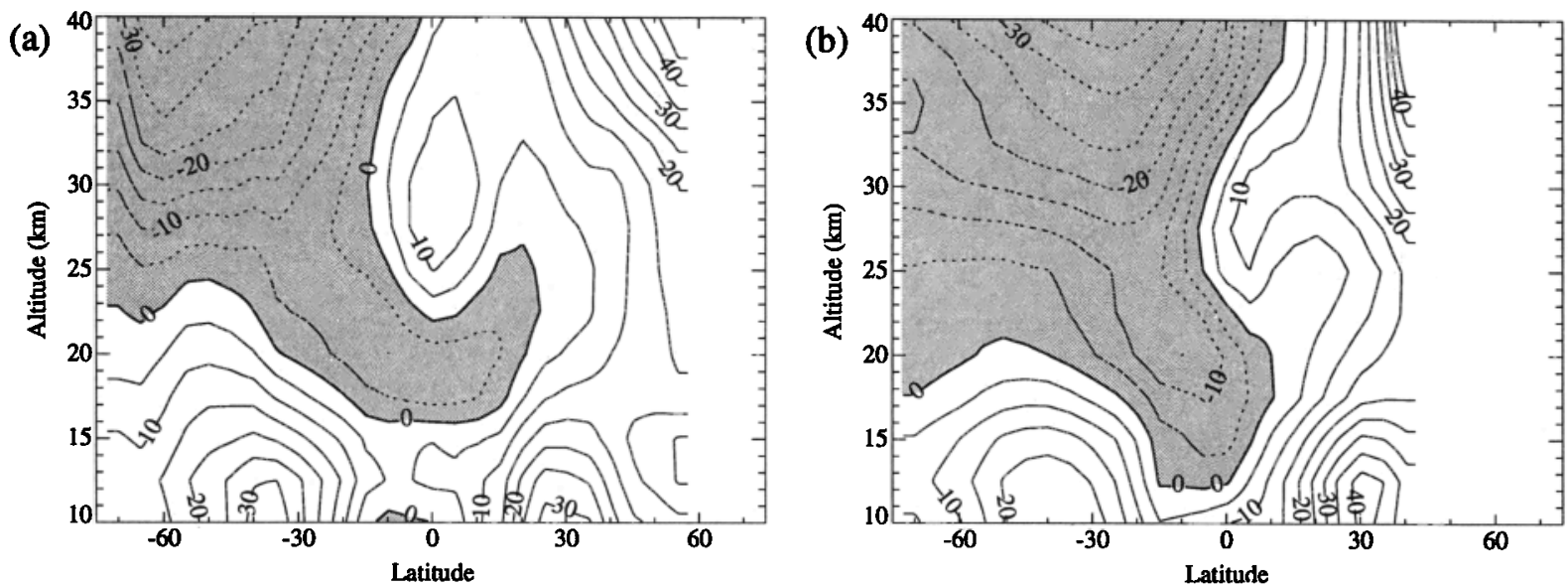

Figure 2. Latitude-height cross sections of HRDI mean zonal winds for (a) November 15-30, 1994, and (b) December $15-31,1994$. The contour interval is $5 \mathrm{~m} / \mathrm{sec}$. 


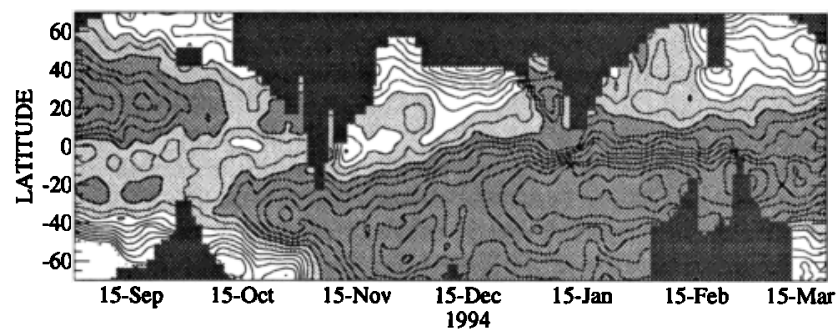

Figure 3. Time-latitude cross sections of mean zonal winds at 35 $\mathrm{km}$. The contour interval is $5 \mathrm{~m} / \mathrm{sec}$, easterlies are darkly shaded and westerlies below $10 \mathrm{~m} / \mathrm{sec}$ are lightly shaded.

periods of acceleration and deceleration, presumably due to fluctuations of the strength of the meridional circulation and intermittent periods of wave forcing. Note in particular the brief subtropical decelerations that coincide with the time of the Rossby wave events shown in Fig. 1. In contrast, QBO westerlies at $30 \mathrm{~km}$ (see Fig. 2) are only shifted slightly into the northern subtropics throughout the winter and disappear in the spring.

Figure 4 shows the Eliassen-Palm cross section for the quasistationary wave number 1 Rossby wave that was present in the wind field at the end of November 1994 and the contours of the body force $D_{F}$. This cross section indicates that significant mean flow deceleration can occur in the tropics and suggests that there is some cross-equatorial propagation of the wave. Strong radiation into the tropics occurs between 30 and $40 \mathrm{~km}$. The subtropics below $30 \mathrm{~km}$ have easterly or weak westerly winds (Fig. 2b) and thus planetary wave propagation into the tropics does not occur.

The momentum budget of the tropical and subtropical stratosphere is a delicate balance of contributions from four sources: meridional vorticity flux, body forces from vertically propagating equatorial and gravity waves, body forces from laterally propagating Rossby waves, and vertical advection of momentum. This balance is described by the transformed Eulerian mean momentum equation [Andrews et al., 1987]

$$
\bar{u}_{t}-v^{*}\left(f-\bar{u}_{y}\right)+w^{*} \bar{u}_{z}=D_{F} .
$$

The mean zonal wind acceleration $\bar{u}_{t}$, the zonal mean absolute vorticity $f-\bar{u}_{y}$, and the Rossby wave contribution to $D_{F}$ were computed for November 1994 from HRDI wind measurements. The residual mean meridional velocity $v^{*}$ was computed from the United Kingdom Meteorological Office assimilation model [Swinbank and O'Neill, 1994] data for the same period. This is probably only qualitatively correct, but does show northward cross-equatorial flow of about $0.5 \mathrm{~m} / \mathrm{sec}$ at $35 \mathrm{~km}$, in agreement with calculations by Eluszkiewicz et al. [1996]. An attempt to deduce the equatorial and gravity wave contribution to $D_{F}$ as a residual of the other terms requires greater accuracy than can be achieved at this point. These computations show that deceleration in the southern subtropics is due to equatorward momentum advection. North of the equator, momentum advection alone would cause an acceleration that increases with latitude. This is largely offset by the Rossby wave body force. It is also possible that gravity waves with easterly phase speed contribute to a net easterly body force as well, since westerly gravity waves will be partially filtered out by the underlying QBO westerlies at the equator and by the subtropical westerly jet at the tropopause. It can be seen in Fig. 3 that after the late November Rossby wave event, acceleration of the zonal wind in the northern subtropics does occur as the westerlies are advected northward.
The body force $D_{F}$ due to stationary Rossby waves was computed from monthly averaged HRDI winds throughout the observation period. A time-latitude cross-section (Fig. 5) at 35 $\mathrm{km}$ shows that deceleration in the northern subtropics occurs only in early winter, and that this deceleration occurs closer to the equator during the westerly QBO years 1992 and 1994 . Later in the winter, easterly body forcing is generally confined to the midlatitudes. The pattern in the southern hemisphere seems less regular. Subtropical penetration of Rossby waves from the south occurs in October 1992, August 1993, June 1994 and September 1994. Note that the only apparent Rossby wave drag in the tropics arising from the southern hemisphere in June 1994 also corresponds to the only time that westerlies extended from the southern hemisphere into

\section{Discussion}

HRDI wind observations show that equatorward propagation of Rossby waves is modulated by the QBO. This has also been noted in the modeling studies of O'Sullivan and Chen [1996] and O'Sullivan [1997]. This modulation of the propagation characteristics is thought to be responsible for the QBO-like variations in midlatitude dynamics [Holton and Tan, 1980; Dunkerton and Baldwin, 1991; O'Sullivan and Dunkerton, 1994]. Rossby wave propagation into the tropics also affects tracer distributions there, and an understanding of how Rossby waves behave as they enter the tropics is essential for understanding the complete picture of how such tracers are transported between the tropics and midlatitudes. The modeling studies of $O$ 'Sullivan and Chen [1996] and Chen [1996] show that this transport behavior is also dependent on the phase of the QBO, with more mixing out of the tropics into the winter hemisphere during easterly QBO phase and with waves passing through the tropics and causing mixing into the summer hemisphere when the tropical winds are westerly. Other observational evidence for this cross-equatorial propagation in $\mathrm{N}_{2} \mathrm{O}$ distributions is discussed by Dunkerton and O'Sullivan [1996] and O'Sullivan [1997].

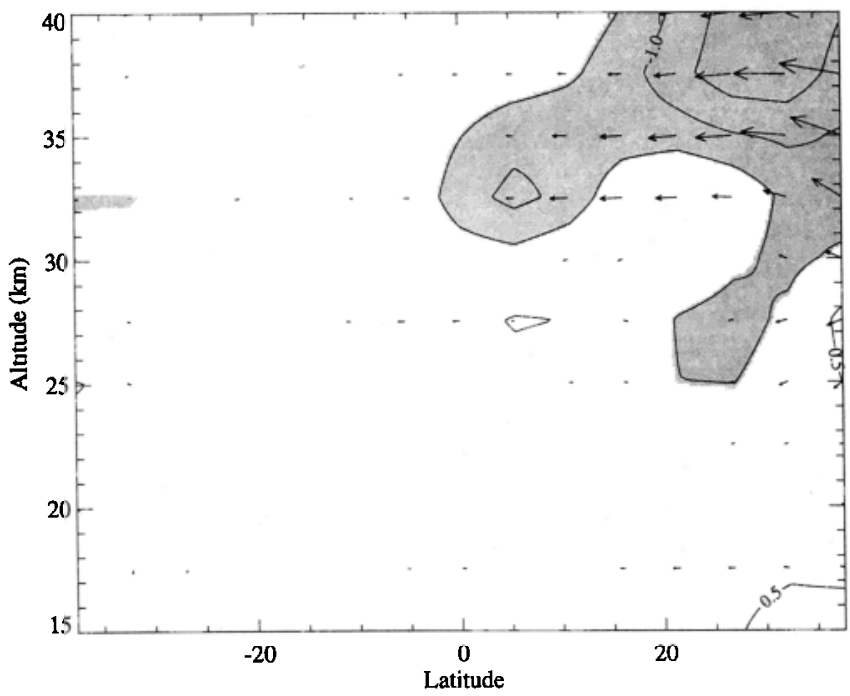

Figure 4. Eliassen-Palm cross sections for the quasi-stationary wave number 1 Rossby wave calculated from HRDI wind data averaged from November 15 to 30,1994 . Eliassen-Palm flux vectors $F$ are divided by the density and scaled so that they point in the direction of wave propagation. Their lergths are thus proportional to the wave activity per unit mass. Contours of the Rossby wave body force $D_{F}$ are overlaid, at $0.5 \mathrm{~m} / \mathrm{sec} /$ day intervals, with values over $0.25 \mathrm{~m} / \mathrm{sec} /$ day shaded. 


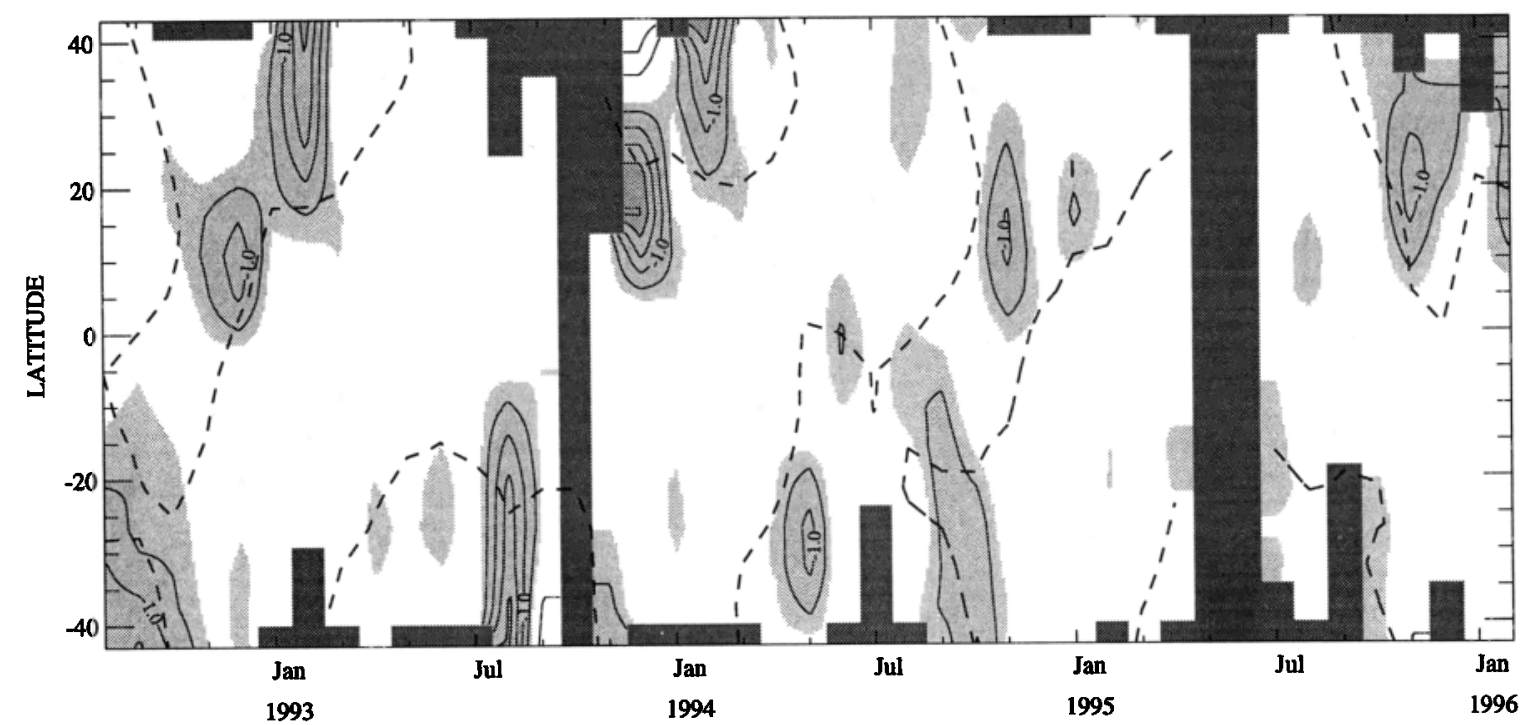

Figure 5. Time-latitude cross section of the stationary wave body force $\left(D_{F}\right)$ at $35 \mathrm{~km}$, calculated from monthly and zonally averaged HRDI zonal winds. The contour interval is $0.5 \mathrm{~m} / \mathrm{sec} /$ day, and easterly forcing is above $0.25 \mathrm{~m} / \mathrm{sec} /$ day is shaded. The zero contour is omitted. The zero wind line is shown as a dashed contour.

The main effect of the Rossby wave body force in the tropics at $35 \mathrm{~km}$ is to cause a more rapid onset of easterlies than would occur from a mean meridional circulation alone. A meridional circulation into the winter hemisphere initially produces westerly acceleration in the winter subtropics, which is offset by the planetary wave drag. This contributes to the formation of a vertical easterly shear zone uniformly across the tropics that becomes the next easterly phase of the QBO. This appears to be the course of events for the QBO cycles observed by HRDI, which fall into the "two-year" cycle classification of Dunkerton and Delisi [1997]. The "three-year" cycles in their classification are characterized by a slower rate of easterly shear zone descent, and one might speculate that this is the result of weaker tropical Rossby wave drag at the beginning of these cycles.

Meridional advection is also present at $30 \mathrm{~km}$, as is evident from the northward shift of the QBO westerlies (Fig. 2), but it does not eliminate the westerlies altogether, as happens at $35 \mathrm{~km}$. The rapid demise of westerlies at $35 \mathrm{~km}$ when they are present in early northern winter, and not at $30 \mathrm{~km}$, may be due to the stronger meridional wind. This paper shows, however, that there is evidence that direct Rossby wave body forcing can also be responsible, since these waves do penetrate into the tropical upper stratosphere.

Acknowledgments. The author thanks Donal O'Sullivan, Tim Dunkerton and an anonymous reviewer for many helpful comments. Deborah Eddy provided expert assistance with preparation of the manuscript. This work was supported by NASA contract NAS 5-27751.

\section{References}

Andrews, D. G., J. R. Holton, and C. B. Leovy, Middle Atmosphere Dymamics, 489 pp., Academic, San Diego, Calif., 1987.

Chen $P$., The influence of zonal flow on wave breaking and tropicalextratropical interaction in the lower stratosphere, J. Atmos. Sci., 54, 2379-2392, 1996

Delisi, D. P., and T. J. Dunkerton, Seasonal variation of the semiannual oscillation, J. Atmos. Sci., 45, 2772-2787, 1988.
Dunkerton, T. J., Laterally propagating Rossby waves in the easterly acceleration phase of the quasi-biennial oscillation, AtmosphereOcean, 21, 55-68, 1983.

Dunkerton, T. J., and M. P. Baldwin, Quasi-biennial modulation of planetary wave fluxes in the northem hemisphere winter, J. Atmos. Sci., 48, 1043-1061, 1991.

Dunkerton, T. J., and D. O'Sullivan, Mixing zone in the tropical stratosphere above $10 \mathrm{mb}$, Geophys. Res. Letts., 23, 2497-2500, 1996.

Dunkerton, T. J., and D. P. Delisi, Interaction of the quasi-biennial oscillation and the stratopause semiannual oscillation, $J$. Geophys. Res., in press, 1997.

Edmon, H. J., Jr., B. J. Hoskins, and M. E. McIntyre, Eliassen-Palm cross sections for the troposphere, J. Atmos. Sci., 37, 2600-2616, 1980.

Eluszkiewicz, J. et al., Residual circulation in the stratosphere and lower mesosphere as diagnosed from microwave limb sounder data, $J$. Atmos. Sci., 53, 217-240, 1996.

Hamilton, K., and J. D. Mahlman, General circulation model simulation of the semiannual oscillation of the tropical middle atmosphere, $J$. Atmos. Sci., 45, 3212-3235, 1988.

Holton, J. R., and H.C. Tan, The influence of the equatorial quasibiennial oscillation on the global circulation at $50 \mathrm{mb}, J$. Atmos. Sci, 37, 2200-2208, 1980.

Ortland, D. A., W. R. Skinner, P. B. Hays, M. D. Burrage, R. S. Lieberman, A. R. Marshall, and D. A. Gell, Measurements of stratospheric winds by the High Resolution Doppler Imager, $J$. Geophys. Res., 101, 10,251-10,363, 1996.

O'Sullivan, D., Cross-equatorially radiating stratospheric Rossby waves, Geophys Res. Lett., in press, 1997.

O'Sullivan, D., and T. J. Dunkerton, Seasonal development of the extratropical QBO in a numerical model of the middle atmosphere, $J$. Atmos. Sci., SI, 3706-3721, 1994.

O'Sullivan, D., and P. Chen, Modeling the quasi-biennial oscillation's influence on isentropic tracer transport in the tropics, J. Geophys. Res., $101,6811-6822,1996$.

Swinbank, R., and A. O'Neill, A stratosphere-troposphere data assimilation system, Min. Wea. Rev., 122, 686-702, 1994.

D. Ortland, Space Physics Research Laboratory, University of Michigan, 2455 Hayward Street, Ann Arbor, MI 48109-2143. (e-mail: ortland@sprlj.sprl.umich.edu)

(Received May 5, 1997;

accepted June 19, 1997.) 